\title{
Extraction of Accommodation Evaluation by Foreign Tourists with Text Mining
}

\author{
Koichi Tsujii, Masakazu Takahashi, Yoshikatsu Fujita, and Kazuhiko Tsuda
}

\begin{abstract}
While the number of foreign tourists visiting Japan is increasing in recent years, online hotel reservation systems are widely used for travel planning. Hotel reservation service sites provide accommodation information both of the features and the recommended points to the potential users. The hotel reservation services users usually refer the other users' reviews in their decision-making. It is useful information for the accommodation service improvement, whereas the replies of users' reviews are at their will. Most of the reviews are not classified appropriately for users' purposes that make it hard to reach the appropriate information in reservation. To solve this problem, this paper provides a method to analyse user reviews in order to capture the characteristic expressions according to their purposes and examines some methods to present beneficial information at the time of hotel service improvement. Moreover, the characteristics of user comments are distinguished for every hotel. Differences between the expressions and the evaluations each hotel is found from the results of the analysis.
\end{abstract}

Index Terms-Evaluation extraction, hotel, reservation, text mining, user review.

\section{INTRODUCTION}

Japanese government is promoting a nationwide project known as Visit Japan to expand the number of foreign tourists since 2003 [1]. This project aims at making 30 million people increase the number of foreign tourists to Japan according to the plan. In order to achieve the goal, it is important to advertise Japan effectively as a priority tourist destination and act upon criticisms made by foreign tourists during their stay. To learn how foreign tourists feel about Japan, we can analyse reviews and comments written on message boards on various travel reservation websites, which reveal their impressions, observations and the highlights of their stay in Japanese hotels.

By analysing the information, the hotel can improve their services and provide satisfaction to many guests.

Although most of the Japanese hotels are currently is

Manuscript received October 10, 2013; revised December 17, 2013.

Koichi Tsujii is with the Graduate School of Systems and Information Engineering, The University of TSUKUBA, Tokyo, CO 112-0012 Japan and with Nippon Travel Agency Co., Ltd, Tokyo, CO 105-8606 Japan (e-mail: s1330182@u.tsukuba.ac.jp).

Masakazu Takahashi is with the Graduate School of Innovation and Technology Management, Yamaguchi University, Yamaguchi, CO 755-8611 Japan (e-mail: masakazu@ yamaguchi-u.ac.jp).

Yoshikatsu Fujita is with the Teikyo University, Tokyo, CO 192-0395 Japan (e-mail: fujita@main.teikyo-u.ac.jp).

Kazuhiko Tsuda is with the Graduate School of Business Sciences, The University of TSUKUBA, Tokyo, CO 112-0012 Japan (e-mail: tsuda@gssm.otsuka.tsukuba.ac.jp). reluctant to welcome the foreign tourists [2]. This is because of the custom differences and the language barrier. From this reason, we focus on the information extraction for welcoming the foreign tourists.

In this paper, we extract information of evaluating points for foreign tourists from the hotels reviews posted by foreign tourists. Section II introduces related work and basic concepts. Section III shows the feature of user review and comparison of the difference in the numerical evaluation criteria of the user review in overseas travel reservation websites and domestic travel reservation websites. Section IV explains the method in text mining analysis of the comments. Section V describes analysed the user review of the foreign visitor stayed in Kyoto area with the proposed method in Section IV. Concluding Remarks and future work are in Section VI.

\section{BACKGROUNDS AND PREVIOUS RESEARCH}

Information on Internet also plays an important role for travel planning. Hotel reservation websites provide not only the official information of the accommodations and the availability but the user reviews posted by the guests. The official information is written by the hotel or the travel company and is presented from the supplier's viewpoint. Users are not satisfied with such information now and request the accommodation reviews from the stayed reviewers. Reviews and comments on bulletin boards are particularly influential in choosing accommodations. Review articles become very important not only for the travellers but also for both of the hotels and travel agencies [3]-[8].

However, it is difficult to read large numbers of reviews written on bulletin boards in detail. To solve this problem, several studies have attempted to extract characteristic information using sentiment analysis on message boards. Tanabe et al. proposed a method to extract travellers' opinions from the user reviews by text mining [9]. Tsujii et al. employed text mining for evaluating travellers' impressions and found that their interests varied depending on the areas in which they stayed. They also classified the reviews and the comments on the board into the prepared evaluation categories by analysing their meanings and assigned positive and negative attributes to each expression. The results revealed that users had some strong opinions that did not accurately reflect the numerical evaluations [10], [11].

These studies revealed that the potential users only paid attention to the website reviews in making reservations and the past studies proposed the new methods to evaluate both the large number of reviews and the importance of review 
information. However, they did not distinguish the reviews from the Nationality and propose the effective presentation method for foreigners.

From the results of the related work, this paper proposes a method to extract the information for the foreign tourists from the accommodation reviews in English. We focus on the accommodation reviews from the non-Japanese visitors to extract the evaluate expressions with text mining. For this purpose, we use the accommodation reviews from the foreign tourists to extract the characteristic expression in the reviews. Then, we make comparison the difference between the evaluate expressions and the prepared evaluation categories and propose the appropriate review categories fit for the foreign tourists.

\section{OUTLINE OF USER REVIEWS}

Travel information is anywhere with Internet and the user reviews are important for understanding the hotel amenities. These reviews are usually written by the guests stayed there and are provided by virtually every travel reservation website. The templates for the review are distributed by the site operator. They are very similar with the components: user profile, impression comment and numerical evaluations. Summary of the hotel information is presented to the potential users and the numerical evaluations are determined by the reservation website and the reviewers post their rating. At first, the numerical evaluations of the reservation site are investigated. Table I indicates the numerical evaluation of the major foreign travel reservation site. The domestic reservation sites are listed in Table II [12]-[20].

TABLE I: OVERSEAS TRAVEL RESERVATION SITES

\begin{tabular}{|c|c|c|c|c|}
\hline & Booking & Agoda & HotelClub & Expedia \\
\hline Hotel Condition & Clean & $\begin{array}{l}\text { Hotel Condition } \\
\text { Cleanliness }\end{array}$ & Amenities & Hotel condition \\
\hline Room Condition & Comfort & $\begin{array}{l}\text { Room Comfort } \\
\text { Standard }\end{array}$ & $\begin{array}{l}\text { Room cleanliness } \\
\text { Room comfort }\end{array}$ & \begin{tabular}{|l|} 
Room comfort \\
Room cleanliness \\
\end{tabular} \\
\hline \multirow{2}{*}{$\begin{array}{l}\text { Service and } \\
\text { Staff }\end{array}$} & Services & - & - & Service \& staff \\
\hline & Staff & Staff Performance & Hotel staff & - \\
\hline Location & Location & Location & Location & - \\
\hline Value & Value for money & Value for Money & Value & . \\
\hline Food & - & Food/Dining & 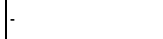 & - \\
\hline
\end{tabular}

\begin{tabular}{|c|c|c|c|c|c|}
\hline & Jalan & $\begin{array}{c}\text { Rakuten } \\
\text { travel }\end{array}$ & Rurubu & Ikyu & Yadoplaza \\
\hline $\begin{array}{l}\text { Hotel } \\
\text { Condition }\end{array}$ & Cleanliness & $\begin{array}{l}\text { Facility } \\
\text { Amenities }\end{array}$ & - & satisfaction & Facility \\
\hline \begin{tabular}{|l|} 
Room \\
Condition \\
\end{tabular} & Room & Room & $\begin{array}{l}\text { Room } \\
\text { facility }\end{array}$ & \begin{tabular}{|l} 
Room \\
amenity
\end{tabular} & cleanliness \\
\hline \multirow{2}{*}{$\begin{array}{l}\text { Service and } \\
\text { Staff }\end{array}$} & Bath & Bath & Bath & Bath & Bath \\
\hline & Service & Service & Service & $\begin{array}{l}\begin{array}{l}\text { Service \& } \\
\text { staff }\end{array} \\
\end{array}$ & Service \\
\hline Location & . & Location & Location & - & Location \\
\hline Value & - & . & . & . & price \\
\hline Food & $\begin{array}{l}\text { Breakfast } \\
\text { Dinner }\end{array}$ & Meal & Food & Food & Food \\
\hline
\end{tabular}

The numerical evaluation criteria that the reservation sites provide are roughly classified into the six categories: 'food', 'price', 'services', 'location', 'room' and 'hotel'. These aspects are important for the guests and are rated on a five- or ten-point scale. In addition to these criteria, the bath is considered important on the Japanese hotel reservation site and reflects the importance of the bathing facilities for the Japanese. In the impression comments, guests can freely describe their impressions and describe their experiences in a way that cannot be expressed in a numerical evaluation. However, many user reviews are posted to the most popular hotels that make it difficult to read and understand all the impression comments. Moreover, the numerical evaluations and the impression comments are considered to be independent, so far. However, there is a relationship among them to be considered. Therefore, we analyse the impression comments using text mining and verified the relevance between the numerical evaluation and the impression comments. In this way, we classified the characteristics of each hotel and proposed an intelligible presentation method for users.

\section{AnAlytical PRocedure}

We analyse the characteristic expressions that appeared in each impression comment using text mining. We count the frequency of each word by the morphological analysis and analyse the tendency of the feature word to attract the user at first. Then, we analyse the feature word and the characteristic expressions that interest users through the dependency analysis to understand the variety of the evaluation that the hotel receives. We divided every evaluation expression into the positive and the negative components and assigned them to the numerical evaluation. Then, we analyse the evaluation of hotels. The analytical flow of text mining using the user reviews is shown in Fig. 1.

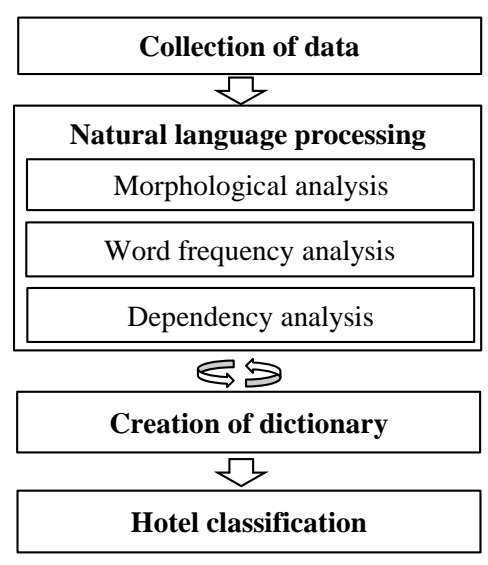

Fig 1. Flow of text mining.

\section{A. Synonym Dictionary}

TABLE III: SAMPLE OF SYNONYM DICTIONARY

\begin{tabular}{|c|c|c|c|c|}
\hline Synonym & \multicolumn{4}{|c|}{ alternative impression } \\
\hline bath & bathroom & bathtub & bath/spa & showerroom \\
\hline staff & concierge & porter & hotel clerk & bell boy \\
\hline bed & bedding & mattress & & \\
\hline internet & wifi & wi-fi & lan & \\
\hline
\end{tabular}

The reviews varied in their means of expression when it came to identical content, such as 'bath room' and 'bath tub', or 'staff' and 'hotelman'. We made clusters of attributes that 
frequently appeared and created a dictionary of synonyms that organised words expressing the same meaning. Then, to improve the classification precision, we corrected the dictionaries on the basis of text mining research and result analysis. The sample of the synonym dictionary is shown in Table III.

\section{B. Numerical Evaluation Dictionary}

User reviews consist of impression comments and numerical evaluation criteria, and we examine how to associate them using a numerical evaluation dictionary. Confirming each of the evaluation expressions, we classified each feature word into six kinds of numerical evaluation frequently used at the travel reservation websites shown in section 3: room, accommodation, food, service, price and location. Through these processes, we gave the hierarchical concept of the numerical evaluation criteria as a typical feature item, and the feature word as the detailed item. We did not perform dictionary registration at the time of classification for words and synonyms which were not applied to the numerical evaluation criteria. The relationship between synonyms and the numerical evaluation criteria is shown in Fig 2.

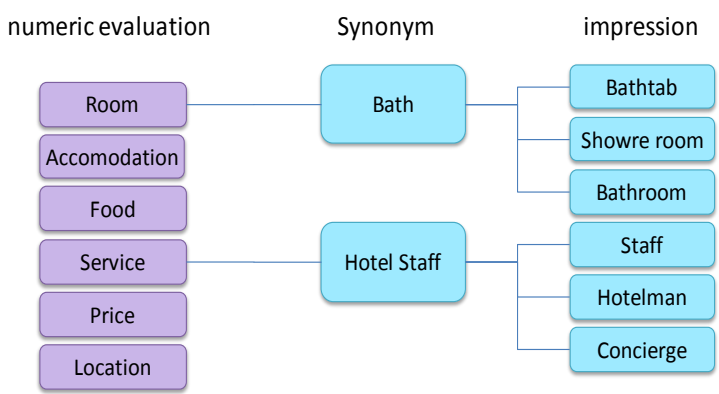

Fig. 2. Relationship between synonyms and numerical evaluation.

\section{Evaluation Attribute Dictionary}

TABLE IV: EVALUATION ATTRIBUTE DICTIONARY

\begin{tabular}{|ll|ll|}
\hline $\begin{array}{l}\text { numerical } \\
\text { evaluation }\end{array}$ & positive evaluation & $\begin{array}{l}\text { numerical } \\
\text { evaluation }\end{array}$ & negative evaluation \\
\hline \hline Location & location-great & Room & room-small \\
Location & location-good & Room & size-small \\
Service & staff-helpful & Hotel & hotel-old \\
Room & room-clean & Hotel & hotel-small \\
Service & staff-friendly & Hotel & hotel-bad \\
Hotel & hotel-nice & Room & bath-small \\
Location & location-convenient & Value & price-expensive \\
Hotel & hotel-great & Value & value-bad \\
Hotel & hotel-good & Hotel & hotel-expensive \\
Service & service-good & Room & room-overpriced \\
\hline
\end{tabular}

To evaluate an impression comment, we labelled positive and negative polarities to the dependency relationship of a feature word and an evaluation word, and built the evaluation attribute dictionary. Using the numerical evaluation dictionary, we connected the feature words of users' impression comments with the numerical evaluation criteria and categorised them as 'positive' or 'negative' in the evaluation attribute dictionary, as shown in Table IV.

In the classification process, we excluded unclear or neutral expressions and requirement expressions that had no evaluation polarity. We used the above-mentioned synonym dictionary, the numerical evaluation criteria dictionary and the evaluation attribute dictionary which allowed us to evaluate the characteristic expressions extracted by text mining according to the numerical evaluation criteria. In the following section, we present the result of the analysis.

\section{IMPRESSION COMMENT ANALYSIS}

In this section, the characteristic expressions in the user impression comments using text mining are analysed. The impression comment describes in the comments consist of the user feelings of their stay and is considered to be frank opinion to the accommodation. The impression comment requires much effort more than the numerical evaluation input. The potential users require the promising information such as information of the hotel, their facilities and the neighbour that are not officially announced from the hotel from the impression comment. It is necessary to clarify the extent to which guests were satisfied with the hotel and the neighbour or not to satisfy the users' requests. We collect the characteristic expressions in the impression comments by text mining using the classification method described in section 4 and analyse the expression frequency in the entire target area. Then, we perform correlation between the evaluation expressions and the numerical evaluation criteria and sort them as the positive or the negative evaluation respectively. From the results, we analyse the difference in the numerical evaluation criteria that attracted attention in this area. We make use of the information on Kyoto hotel gathered from the overseas hotel reservation site for the analysis. Analytical data is collected in total of 500 reviews consist from 5 popular reviewed hotels with 100 reviews respectively in the area. We use the Enju as the extraction tool [21].

\section{A. Feature of the Entire Kyoto Area}

Kyoto is one of the most famous cities in Japan and is the historical city popular with the foreign tourists. Many reviews are gathered from the foreign tourists stayed in Kyoto as a result. To investigate how foreign tourists evaluated the site, we analyse the accommodation in the entire Kyoto area. First, we perform text mining of all the review data and calculate the total number of evaluation expressions. The analytical result is shown in Table V.

Foreign tourists show their interests to the location. Many evaluations are seen in the evaluation expressions among the impression comments such as the location, the room, and the service staff from the analysis. The expressions with the positive evaluation scored high in the rank. On the other hand, as for the numerical evaluation to the room, both the positive and the negative evaluations are scored. For example, the negative evaluation expression is seen such as the room is small (room-small).

Next, we combine the evaluation expressions with the six numerical evaluations. The result is shown in Table VI. This 
table assigns the evaluation expression in the impression comment to the numerical evaluation, classifying them into the positive or the negative evaluation with their frequency. This result shows the numerical evaluation is not evaluated uniformly. The users evaluate numerical evaluation in the order of 'location', 'room', 'hotel' and 'service'. This result shows that there is a priority among the numerical evaluation when the foreign tourists post their impressions. It turns out that the foreign tourists do not evaluate all the numerical evaluation equally, but the places are put the importance on the evaluation of the location. Next, the foreign tourists express their opinions about the room where they stayed, followed by the hotel itself and the service. On the other hand, the evaluation of price or the food is hardly indicated by any impression comment. This shows that the foreign tourists have not paid much attention to these numerical evaluations. Travellers may not have meals at the hotel during their stay, or there may be no interest in the meal price. Overall, the positive evaluation expressions have the highest frequency, although the negative expressions also exist. More than half of the negative expressions are for the evaluations of the room.

In the following sections, we see the difference in the evaluation of each hotel in terms of the detailed description of evaluation expressions.

\begin{tabular}{|l|l|lr|}
\multicolumn{2}{c}{ TABLE V: EVALUATION EXPRESSIONS IN KYOTO } \\
\hline $\begin{array}{l}\text { numerical } \\
\text { evaluation }\end{array}$ & evaluation expression & polarity & frequency \\
\hline \hline Location & location-great & positive & 210 \\
Location & location-good & positive & 176 \\
Service & staff-helpful & positive & 95 \\
Room & room-small & negative & 92 \\
Room & room-clean & positive \\
Service & staff-friendly & positive & 91 \\
Hotel & hotel-nice & positive & 76 \\
Location & location-convenient & positive & 68 \\
Hotel & hotel-great & positive \\
Hotel & hotel-good & positive & 48 \\
Service & service-good & positive & 41 \\
Room & room-good & positive & 39 \\
Room & room-comfortable & positive & 37 \\
Room & room-nice & positive & 33 \\
Room & internet-free & positive & 32 \\
Room & room-big & positive \\
Room & room-spacious & positive \\
Hotel & hotel-clean & positive \\
Location & location-nice & 32 \\
Room & room-large & 31 \\
\hline
\end{tabular}

TABLE VI: EVALUATION ACCORDING TO NUMERICAL EVALUATION

\begin{tabular}{|lrrrrrrrr|}
\hline & Location & Hotel & Value & Food & Room & Service & Total \\
\hline Positive & 511 & 225 & 24 & 56 & 278 & 144 & 1238 \\
Negative & 16 & 14 & 1 & 4 & 95 & 6 & 136 \\
\hline \hline Total & 527 & 239 & 25 & 60 & 373 & 150 & 1374 \\
\hline
\end{tabular}

\section{B. Feature Comparison of Individual Hotels}

In the previous sections, we classify review data using all the impression comment data of the Kyoto area. We combine the numerical evaluation criteria with the evaluation expressions, and the priority of topics that most foreign tourists concerns are shown. In this section, we relate the evaluation expression of individual hotels with the numerical evaluation and verify the feature of each hotel. The result of feature classification of each hotel from Hotel 'A' to Hotel ' $E$ ' is shown in Table VII. From the results, we examine the evaluation expressions with the greatest evaluation frequency: 'location', 'room', 'hotel' and 'service'.

TABLE VII: EVALUATION TENDENCY FOR EACH HOTEL

\begin{tabular}{|lrrrrrrrr|}
\hline & Location & Hotel & Value & Food & Room & Service & Total \\
\hline \hline A & $\mathbf{9 8}$ & $\mathbf{4 7}$ & $\mathbf{6}$ & $\mathbf{1 1}$ & $\mathbf{6 2}$ & $\mathbf{3 4}$ & $\mathbf{2 5 8}$ \\
Positive & 97 & 44 & 6 & 10 & 50 & 33 & 240 \\
Negative & 1 & 3 & & 1 & 12 & 1 & 18 \\
B & $\mathbf{9 4}$ & $\mathbf{4 1}$ & $\mathbf{4}$ & $\mathbf{1 6}$ & $\mathbf{7 4}$ & $\mathbf{2 1}$ & $\mathbf{2 5 0}$ \\
Positive & 92 & 39 & 4 & 15 & 59 & 20 & 229 \\
Negative & 2 & 2 & & 1 & 15 & 1 & 21 \\
C & $\mathbf{1 2 1}$ & $\mathbf{3 2}$ & $\mathbf{4}$ & $\mathbf{4}$ & $\mathbf{1 0 0}$ & $\mathbf{3 7}$ & $\mathbf{2 9 8}$ \\
Positive & 117 & 28 & 3 & 3 & 63 & 35 & 249 \\
Negative & 4 & 4 & 1 & 1 & 37 & 2 & 49 \\
D & $\mathbf{1 1 1}$ & $\mathbf{4 3}$ & $\mathbf{9}$ & $\mathbf{1 2}$ & $\mathbf{6 4}$ & $\mathbf{3 0}$ & $\mathbf{2 6 9}$ \\
Positive & 105 & 40 & 9 & 12 & 47 & 29 & 242 \\
Negative & 6 & 3 & & & 17 & 1 & 27 \\
E & $\mathbf{1 0 3}$ & $\mathbf{7 6}$ & $\mathbf{2}$ & $\mathbf{1 7}$ & $\mathbf{7 3}$ & $\mathbf{2 8}$ & $\mathbf{2 9 9}$ \\
\hline Positive & 100 & 74 & 2 & 16 & 59 & 27 & 278 \\
Negative & 3 & 2 & & 1 & 14 & 1 & 21 \\
\hline
\end{tabular}

First, we consider the condition of location. For every hotel, the evaluation expression for location is written about the most, particularly with regard to the Hotel ' $C$ ' and the Hotel ' $\mathrm{D}$ '. Accommodation guests of these hotels evaluate the condition of location as the most significant with many evaluation expressions such as 'location-good', 'location-great' seen and many expressions about the distance to a nearby station include. Moreover, the proximity to the high street, the distance to the famous sightseeing spot or the surrounding shopping mall are also the common topics. It turns out that the location is an important factor among the numerical evaluation and is a priority consideration issues for many guests.

Next, we consider the evaluation of the room, for which the frequency of evaluation expressions is the second highest. In these evaluations, the expressions such as 'room-nice' and 'room-clean' are seen as the positive. The evaluation expressions for the room facilities, such as the bed, TV set or bathroom, are not seen much. On the other hand, many negative expressions are seen on the topic of rooms, particularly with regard to where the evaluation expression of 'room-small' is written. This evaluation expression shows dissatisfaction with the room which the guest used was too small. From this, potential users would check the description of the size of the rooms. For the hotel, many evaluation expressions regarding the hotel equipment and the hotel itself are seen. There are expressions about the overall impression of the hotel itself as the feature expressions, such as 'hotel-nice' and 'hotel-great'. Many evaluations of the entire 
hotel are seen but the evaluations of incidental facilities, such as lobby, elevator, and wash location are made by only a few. In the evaluation of services, reception of the hotel staff ranked highly most. The guests evaluate the staff with high quality and friendly as detailed expressions such as 'Staff-helpful' and 'Staff-friendly'. Furthermore, the expressions like 'having provided good service although the hotel staff could hardly use English' are seen. This shows the Japanese hotel staffs need to improve their language skills. Next, we inspect the rate of incidence of the frequency of evaluation list expression by each numerical assessment of 5 hotels. The results are shown in Table VIII. However, three negative expression of numerical evaluation items such as 'food' , 'value', and 'service' that frequency are less than 10 times are excluded.

TABLE VIII: FREQUENCY OF RELATIVE NUMERICAL VALUE EVALUATION

\begin{tabular}{|lrrrrrr|}
\hline & Location & Hotel & Value & Food & Room & Service \\
\hline \hline \multicolumn{2}{|l}{ Positive evaluation } & & & & & \\
\hline A & $19 \%$ & $20 \%$ & $25 \%$ & $18 \%$ & $18 \%$ & $23 \%$ \\
B & $18 \%$ & $17 \%$ & $17 \%$ & $27 \%$ & $21 \%$ & $14 \%$ \\
C & $\mathbf{2 3 \%}$ & $12 \%$ & $13 \%$ & $5 \%$ & $\mathbf{2 3 \%}$ & $\mathbf{2 4 \%}$ \\
D & $21 \%$ & $18 \%$ & $\mathbf{3 8 \%}$ & $21 \%$ & $17 \%$ & $20 \%$ \\
E & $20 \%$ & $\mathbf{3 3 \%}$ & $8 \%$ & $\mathbf{2 9 \%}$ & $21 \%$ & $19 \%$ \\
Negative evaluation & & & & & \\
A & $6 \%$ & $21 \%$ & - & - & $13 \%$ & - \\
B & $13 \%$ & $14 \%$ & - & - & $16 \%$ & - \\
C & $25 \%$ & $\mathbf{2 9 \%}$ & - & - & $\mathbf{3 9 \%}$ & - \\
D & $\mathbf{3 8 \%}$ & $21 \%$ & - & - & $18 \%$ & - \\
E & $19 \%$ & $14 \%$ & - & - & $15 \%$ & - \\
\hline
\end{tabular}

This Table shows the percentage of the evaluation expression for the numerical evaluation criteria appeared in each hotel. First, we divide them into positive and negative, and then evaluate the ratio of evaluation expression among those hotels. When the evaluation expression appears more frequently in a certain hotel than others, the relative appearance ratio becomes higher than other hotels. This clearly shows that the evaluation expression designates the feature of that hotel. Let us see the positive evaluation. In case of the Hotel ' $\mathrm{C}$ ', it gains positive evaluation for the location, room and service. Next, in case of the Hotel ' $E$ ', it is highly evaluated for the food and hotel, while in case of the Hotel 'D', it obtain relatively higher points in 'value'. Then, we examine the results of the negative expressions. In case of the Hotel ' $C$ ', it receives relatively higher negative evaluation in the hotel and room among 5 hotels. As the Hotel ' $C$ ' occupied relatively higher position in positive expression, this hotel is regarded as having pros and cons upon users' preference. In case of the Hotel 'D', location is evaluated negative, but the Hotel ' $\mathrm{D}$ ' gain higher evaluation in value. This explains the Hotel ' $D$ ' is mainly focused on location and price.

Thus, we can express the feature of each hotel in same area by referring to relative positive and negative evaluations of a hotel. In this way, we can show a potential user the numerical evaluation criteria that attracted the most attention from guests. We can offer an index for users to choose the most suitable accommodation for their travelling purposes.

\section{Improvement Items to the Hotel}

In this section, we propose new reference index that is helpful for finding hotel's strengths and weaknesses by interpreting data in Table VIII. By comparing the distribution of users' evaluation expression, opinion and comments for each accommodation, we can tell which index should be important for improving weakness and enhancing strength.

If hotels would investigate specific evaluation results after obtaining numerical evaluation, the hotel should refer the impression comment written by users. Hotel can improve their position in the area by considering the results of such analysis. If users have focused especially on location, it is not possible to change the location itself, but by providing detailed information about their accessibility, potential users will choose the hotel with confidence. In the same manner, it is not possible to change the size of its room, but by advertising their enhancement for toiletries and room functional facilities, it will be possible to improve the evaluation. Moreover, a competitive advantage index can be found by comparing with the average evaluation information level of surrounding hotels. By making use of such information, hotel will be able to obtain competitive superiority.

In this Section, we analyse the hotel reviews using impression comments. We sum the feature expressions from the guests' impression comments and create a combination with the feature expression and numerical evaluation criteria of an impression comment. Next, we propose how to complement two evaluation criteria, the independent numerical evaluation and an impression comment. It turn out that a user does not evaluate all numerical evaluation criteria to the same degree, but instead writes impression comments focusing on just some of the evaluation criteria. We classify characteristic expressions into positive and negative evaluations, and can judge the importance for every numerical evaluation criteria. We perform a relative evaluation in an area by comparing the gap between numerical evaluation averages of the entire area and the numerical evaluations of hotels. Using this method, we can provide useful information not only to users but hotels.

\section{CONCLUDING REMARKS}

We make text mining analysis of visitors' impression comments, and extract items of their interests and evaluation expressions. We combine the evaluation expression and the numerical evaluation. Then verify numerical evaluation that attracts the guests' interest. We make comparison with this procedure for 5 hotels in Kyoto. We capture the difference of numerical evaluation that draws the guests' interest in each hotel. Then, examine the relative differences of the numerical evaluation of each hotel, and propose new reference index that is helpful for finding hotel's strengths and weaknesses. An impression comment is a description which is only made by a guest who has actually used the accommodation.

In Japan, where the language barrier is prevalent for foreign tourists, the impression comment of a user review written in a potential user's native language serves as a reassuring source of information. Although Japan is promoting a campaign to increase foreign tourists, no study of the accommodation evaluation using the impressions comments written by foreign tourists has yet been conducted. 
Improving the service to foreign tourists by referring such information which is not contained in hotel-provided information is important even for the hotel.

Our future work includes, 1) presenting the evaluated information for each hotel in real-time by employing dynamic text-mining 2) automatic extraction of the impression comment from users' review that is helpful for hotels' service improvement.

We will pursue the goal of presenting more helpful information to foreign tourists who are looking for hotel, and hotels that want to improve their services, and then contribute to increase the number of foreign tourists by enhancing our analysis method.

\section{REFERENCES}

[1] Japan Tourism Agency. (2012). Inbound travel promotion project (Visit Japan Project). [Online]. Available: http://www.mlit.go.jp/kankocho/en/shisaku/kokusai/vjc.html

[2] International Hospitality and Conference Service Association. (2010) The examination about acceptance of an foreign visitor (Japanese). [Online]. Available: http://inboundcafe.ihcsa.or.jp/bindata/upfile/00000016.pdf

[3] U. Gretzel and H. Y. Kyung, "Use and impact of online travel reviews," Information and Communication Technologies in Tourism, pp. 35-46, 2008.

[4] P. O. Connor, W. Höpken, and U. Gretzel, Information and Communication Technologies in Tourism, Vienna: Springer Vienna, 2008.

[5] I. E. Vermeulen and D. Seegers, "Tried and tested: The impact of online hotel reviews on consumer consideration," Tourism Management, vol. 30, no. 1, pp. 123-127, 2009.

[6] L. Zhang, B. Pan, W. Smith, and X. Li, "An exploratory study of travellers' use of online reviews and recommendations," Information Technology \& Tourism, vol. 11, pp. 157-167, 2009.

[7] I. E. Vermeulen and D. Seegers, "Tried and tested: The impact of online hotel reviews on consumer consideration," Tourism Management, vol. 30, no. 1, pp. 123-127, 2009.

[8] B. A. Sparks and V. Browning, "The impact of online reviews on hotel booking intentions and perception of trust," Tourism Management, vol. 32 , no. 6, pp. 1310-1323, 2011.

[9] W. Tanabe and M. Goto, "One Consideration about the User Review Analysis to Support the Strategic Construction of the Accommodations," The Musashi Institute of Technology Environmental Information Department Information Media Center Journal, vol. 9, 2008

[10] K. Tsujii, T. Ikoma, and K. Tsuda, "An evaluation method for segmental accommodation reviews with text mining," Frontiers in Artificial Intelligence and Applications, vol. 243, pp. 893-900, 2012.

[11] K. Tsujii and K. Tsuda, "The attention information extraction method from a stay review using text mining," Journal of Digital Practices, vol. 3, pp. 289-296, 2012.

[12] Agoda. (September 2012). Discount Hotel Reservations Worldwide. [Online]. Available: http://www.agoda.com/

[13] Booking. (September 2012). [Online]. Available: http://www.booking.com/

[14] Expedia. (September 2012). [Online]. Available: http://www.expedia.co.jp/
[15] HotelClub. (September http://www.hotelclub.co.jp/

[16] Ikyu. (September 2012). [Online]. Available: http://www.ikyu.com/

[17] Jalan. (September 2012). [Online]. Available: http://www.jalan.net/

[18] Rakuten travel. (September 2012). [Online]. Available: http:// www.travel.rakuten.co.jp/

[19] Rurubu travel. (September 2012). [Online]. Available: http:// www.rurubu.travel/

[20] Tabiplaza. (September 2012). [Online]. Available: http://www.tabiplaza.net/

[21] Enju. (June 2013). A fast, accurate, and deep parser for English. [Online]. Available: http://www.nactem.ac.uk/enju/

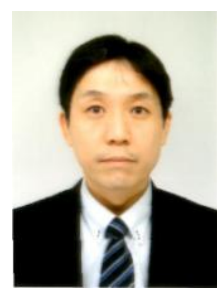

Koichi Tsujii received the master of business administration from University of Tsukuba in 2012. He has been working at Nippon Travel Agency Co. since 2001. His research interests include action of the traveller on websites, text mining of traveller's review. $\mathrm{He}$ is a member of IPSJ and JSAI.

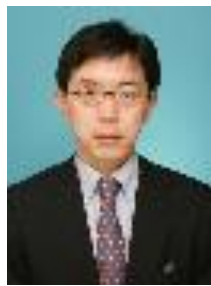

Masakazu Takahashi received his MBA degree in 1996 and $\mathrm{PhD}$ in 2010 both from the University of Tsukuba, Japan. He started his business carrier from Nikkei Research, a subsidiary of Nikkei: Japanese newspaper corporation, in 1992, and started his educational carrier from Gunma University in 2010.

$\mathrm{He}$ is presently an associate professor at the Graduate School of Innovation and Technology Management, Yamaguchi University from 2012. His research interests include computational organization theory, cooperative agents, case-based reasoning, and service science and knowledge system development methodology. He is a member of IEEJ, IPSJ, JSAI, and ACM.

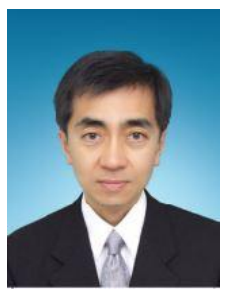

Yoshikatsu Fujita received the master of science in computer science from Georgia Institute of Technology in 1994, and the Ph.D. in Systems Management from University of Tsukuba in 2009. He was with Panasonic Corporation during 1984-2009.

He is presently an associate professor at Department of Sociology, Teikyo University. His research interest include overlay network, digital TV and social media. $\mathrm{He}$ is a member of IPSJ, IEICE and JASMIN.

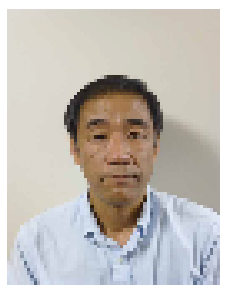

Kazuhiko Tsuda received the B.S. and Ph.D. degrees in Engineering from Tokushima University in 1986 and 1994, respectively. He was with Mitsubishi Electric Corporation during 1986-1990, and with Sumitomo Metal Industries Ltd. during 1991-1998.

$\mathrm{He}$ is presently with the Graduate School of Business Science, University of Tsukuba, Tokyo, Japan as an associate professor during 1998-2005, and as a professor since 2005. His research interests include natural language processing, database, information retrieval and human-computer interaction. He is a member of The Information Processing Society of Japan and The Institute of Electronics, Information and Communication Engineers. 